\title{
The Empirical Study of English Teaching Flip Class Based on MOOC Education
}

\section{Juan Chen}

\author{
Sichuan Vocational \& Technical College, Suining, Sichuan, 629000
}

\author{
Keywords: Flip Class, MOOC, English Teaching, Empirical Study
}

\begin{abstract}
Flip classroom teaching mode as an emerging educational technology has effectively promoted the improvement of classroom teaching effectiveness and teaching goals, achieved personalized learning. At the same time, it can promote the improvement of students' communicative competence, autonomous learning ability and cooperative learning ability. Based on the reality of the branch of Chinese English teaching in Chinese culture, this study takes the literature research, experimental research and action research as the basic research methods, tries to apply this model in the actual teaching of college English, and explores how to improve the quality of college English teaching and promote students' enthusiasm. In the process of research, the paper tested different teaching objectives reflected in the teaching model differences, trying to use flip classroom teaching model to truly improve teaching quality, develop students' overall quality. It hopes to provide some reference for the future flip classroom in college English Teaching.
\end{abstract}

\section{Introduction}

As an important position of personnel training, colleges and universities have a large number of people and diverse disciplines, and should pay more attention to the changes of educational technology and teaching methods in order to meet the demand of individualized education in colleges and universities. This article will explore the practical effect of overturning classroom teaching of professional English in undergraduate teaching, compare the difference between overturning classroom and traditional classroom, whether overturning classroom can stimulate learner's enthusiasm for learning more effectively than traditional classroom, improve teaching quality, the specific implementation process will encounter what problems should be how to solve. In order to speed up the pace of education reform and further promote the information and education in education rooting in education, many scholars and front-line teachers have started to pay attention to overturning classroom teaching methods and gradually tried and explored overturning classrooms suitable for Chinese education. However, teachers' lack of self-confidence and practical experience on how to effectively apply the flip classroom approach in teaching has led teachers not to accurately grasp the essence and content of the flip classroom. At present, the empirical research on exploring flip classrooms mainly focuses on primary and secondary education, and there are relatively few empirical studies on how to implement flip classroom in higher education.

\section{Flip Classroom Teaching Model of Theoretical Exploration}

Grasping the learning method used in teaching practice, embodied in the process of teaching teachers in the class taking into account the individual guidance, they will be in the process of learning through a variety of evaluation methods to give students the necessary feedback and guidance. Evaluation is no longer a manifestation of teacher responsibility in mastering learning classes, but a compass that guides teachers on how to proceed with teaching. Teachers adjust the teaching activities based on the results of the evaluation so that they can be better adapted to each student. Teachers tend to rate students through a standard reference test rather than a regular reference test, which means that instead of competing among groups, students compare themselves to expecting to do their best. How to implement learning strategies? First, students will be confronted with a series of learning content. After completing one phase of study, teachers will test 
the students to see whether the students have mastered the corresponding teaching objectives. If the student has mastered this goal, he will continue with other rich activities to deepen understanding. However, if the student fails to pass the test, the instructor will provide additional guidance and error correction until he successfully passes the exam. The students will receive constructive feedback and have the courage to correct the mistakes until the appropriate teaching objectives are achieved.

Bloom believes that "the essence of mastering learning strategies is group teaching, supplemented by the frequent feedback and individual corrective help each student needs." On the basis that "all students can learn well", first let the students know "what to learn", "how to learn" and to what extent; secondly, to provide students with all the help they need in the learning process, and constantly encourage Students, and establish their confidence and inspire their motivation to learn. Finally, through formative testing found that students in learning defects and progress, as a basis for students to conduct more in-depth or individual guidance. Continuous feedback - the process of correction is really the process for all students to achieve the desired teaching goals for most students. This feedback - corrective system is at the core of "mastery learning."

One of the major factors that Educational Psychology considers to have a significant impact on student learning outcomes is student emotion. During the teaching process, good students, often praised by teachers, have a more positive attitude toward learning, so as to make more efforts to complete their learning tasks on their own initiative. Conversely, "poor students" are influenced by negative emotions and see learning as a burden. Therefore, it is necessary to help students to build up confidence and constantly give feedback to teachers through correction - to give students more successful experiences so as to enable students to see the hope reached by the students and thus encourage students to exert more efforts. Therefore, the positive emotional characteristics of students are the internal factors of "mastery learning".

Teaching evaluation theory is Bloom's "mastering" theory, an important part of, including diagnostic evaluation, formative evaluation and final evaluation." Diagnostic evaluation is an essential part of a good teaching and diagnostic evaluation is to make teaching suitable for learners' needs and backgrounds." As a means of "prior assessment," diagnostic evaluations provide teachers with the problems they face in teaching; examine the students' knowledge of the previous stage; and know how well they are familiar with what they will learn. "Formative evaluation is conducted during the learning phase, and every effort must be made to improve it." In the process of mastery of learning, Bloom puts more emphasis on formative evaluation because it can reflect the problems that occur in the teaching process in real time, so as to adjust the teaching of teachers and correct the students' learning so that the teaching system can truly become a self-correcting system. End-of-line evaluation, also known as "ex-post evaluation," is an assessment of student learning outcomes at the conclusion of a major phase of a course or at the end of a course, which is essentially" a more comprehensive assessment of the larger achievements made in a major part." Three evaluation methods have their own emphasis on teaching, organic combination can not be neglected.

\section{Turn the Implementation of the Classroom Teaching Model in the Course of Chinese Culture}

Elective teaching has always been the focus of 90 minutes of classroom teachers to tell, and flip classroom teaching provides us with a new way of thinking. With the flip classroom teaching mode, we can make students have a general understanding of the content to be learned in a relaxed environment by using videos or tutorials before the class, and most of the time in the classroom can be controlled by the students under the guidance of teachers Personalized learning, the past, "a roll of life and death" assessment model by the formative assessment and the termination of the assessment of a combination of diversified assessment model to be replaced. Therefore, the purpose of clear video and guide case makes the release of classroom time a large number of possible, so as to establish the dominant position of students; students in the classroom involved in teaching activities are closely watched by teachers, in constant feedback - correction, students Learning 
initiative has been improved; the same time, the use of a variety of ways more objective and timely evaluation of students learning effectiveness, so as to successfully complete the mastery and teaching, to master and learn to master the evaluation of teaching practice. We expect the efficiency of flip classroom teaching model can be effectively reflected in college English elective courses, in order to achieve this goal, the author effectively communicate the content of pre-class teaching, meaningful learning and internalization activities in the class effectively And objective evaluation of the effect of after-school learning conducted an active exploration and practice.

In our country, besides using the teaching video which is popular in foreign countries as the medium of teaching content, according to the current national conditions in our country, some schools use paper-based teaching to realize the teaching content transmission. Therefore, in the teaching mode of overturning classroom, Important, but not necessarily essential. In the process of instructional design, we should give full consideration to the compatibility between the purpose of teaching and the video. That is to say, we should carefully consider whether the teaching video is the most suitable means of teaching content transmission compared with other ways. Teaching Content There is no absolute advantage in teaching videos, and we should not "video for video." However, upon the decision of teaching video as the medium of teaching content, front-line teachers will face many difficulties: First, most of the liberal arts teachers are afraid of modern technology and software; second, the content of liberal arts teaching is often not very clear in logic. Therefore, "Once the video is identified as the best way to teach a piece of knowledge, teachers involved in flipped classrooms face significant technical and psychological challenges. In addition to the technical challenges, the complexities of the liberal arts curriculum and loose the structure also makes the teaching of video production more difficult." In teaching practice, the author mainly adopts the existing teaching video and video production in two ways to solve this problem.

The problem of video production arises when the existing video does not exactly match the teacher's teaching goal. When it comes to "teaching videos," most people think of teaching live video recorded with a video camera. Although the teaching live can be completed in the process of teaching a one-time recording, but its higher hardware requirements are not all teachers in all schools can afford to play, and teachers face the cold lens and the face of real students is Two completely different feelings, and even some teachers will not get too nervous. Therefore, we need to find some more simple and more humane ways to improve the efficiency and quality of video production. The easiest way is to use the phone's camera. Fixing the phone to a point where the teacher can take a photo or presentations can be taken by the teacher. The teacher can follow the established way of thinking, during which he can not only hear the teacher clearly, but also can see the teacher's calculation or presentation process. In addition, some commonly used software and external devices in the computer can be used to make higher quality video, such as recording software, screen recording software, audio and video editing software, tablet, micro phone and so on. Slide shows and mouse tracks on the computer operation on the computer screen display content can be recorded software to capture, commonly used, including Camtasia Studio, screen masters, Power Video Maker, etc., PowerPoint 2010 can also be more Save PPT documents as .wmv format for convenience. Audio and video editing software can audio and video files to select, edit, connect and other processing, simple and easy to use, including Cooledit, Video Studio, Adobe Premiere, audio and video formats can be converted between the different formats factory simple and easy to complete.

\section{Conclusions}

In recent years, college English teaching reform from the computer-aided teaching to network platform support for autonomous learning and classroom teaching, flip classroom teaching model is the application of college English classroom reconstruction of a new exploration. Flipped classroom teaching mode applied to college English teaching, especially elective teaching, is a bold attempt to integrate educational technology and college English course. 


\section{Acknowledgements}

Fund: Sichuan provincial subject flip classroom model and then in vocational colleges English teaching application 18SB0710.

\section{References}

[1] Maureen J. Lage, Glenn J. Platt, Michael Treglia. Inverting the Classroom: A Gateway to Creating an Inclusive Learning Environment [J]. The Journal of Economic Education, 2000(1): 30-43.

[2] Kathleen P. Fulton. 10 reasons to flip [J]. Phi Delta Kappan, 2012(2):20-24.

[3] Dan Mac Isaac. “The Flipped Classroom” and Khan Academy video-lecture-basededucational reform discussed by The Economist magazine, MSNBC, Salman Khan, andFrank Noschese [J]. The Physics Teacher, 2011(8): 526.

[4] Graham R. Parslow. Commentary: The Khan academy and the day-night flippedclassroom [J]. Biochemistry and Molecular Biology Education, 2012(5):337-338.

[5] Homeyra R. Sadaghiani. Online Prelectures: An Alternative to Textbook ReadingAssignments [J]. The Physics Teacher, 2012(5):301.

[6] Fulton, Kathleen. The Flipped Classroom: Transforming Education at Byron High School [J]. T H E Journal, 2012(3):18-20. 